\title{
Global convergence in correlations among soil properties
}

\author{
Baicheng Xie ${ }^{1,2,3}$, Chunxia Zhang ${ }^{4}$, Guodong Wang ${ }^{1 *}$, Yingge Xie ${ }^{1}$ \\ (1. College of Science, Northwest A\&F University, Yangling 712100, Shaanxi, China; \\ 2. Institute of Meteorology Science of Hunan Province, Changsha 410118, China; \\ 3. Meteorological Disaster Prevention and Mitigation Key Laboratory of Hunan Province, Changsha 410118, China; \\ 4. Changsha Environmental Protection College, Changsha 410004, China)
}

\begin{abstract}
The correlations among major soil properties at a global scale are essential for explaining the global convergence of ecological processes in terrestrial ecosystems but have never been assessed. In this study, a global soil database was analyzed to determine whether correlations among soil properties were consistent and how such correlations varied among continents and land use types. Across the entire dataset, the electrical conductivity of soils increased significantly with increasing $\mathrm{pH}$; additionally, the total nitrogen and cation exchange capacity increased significantly with increasing organic carbon content, while the organic carbon content and cation exchange capacity decreased significantly with increasing sand content in soil. The correlations between paired soil properties were consistent among continents and land use types. The slopes of the relationships, however, varied significantly by continent and land use type. The results indicated a global convergence of correlations among soil properties and variation in the slopes of specific relationships between paired soil properties among continents and land use types. Such consistent global correlations and different slopes of specific correlations can have important implications in explaining the global patterns of biogeochemical processes and can provide some basis for linking soil resources with ecological processes on a global scale.
\end{abstract}

Keywords: continent, land use, organic carbon, electricity, pH, CEC

DOI: $10.25165 /$ j.ijabe.20201303.4547

Citation: Xie B C, Zhang C X, Wang G D, Xie Y G. Global convergence in correlations among soil properties. Int J Agric \& Biol Eng, 2020; 13(3): 108-116.

\section{Introduction}

The distribution of soil resources and their availability to soil biota and plants determine the evolution and functioning of terrestrial ecosystems at different spatial scales and ecosystem levels ${ }^{[1,2]}$. For example, soil biota and microbial processes depend on the availability and stoichiometry $(\mathrm{C}: \mathrm{N}: \mathrm{P})$ of soil nutrients ${ }^{[3,4]}$. The decomposition of soil organic material and the emission of greenhouse gases driven by microbial processes are often affected by the soil environment and the availability of nutrients ${ }^{[5,6]}$. Foliar and root traits ${ }^{[7,8]}$, plant stoichiometry ${ }^{[9-11]}$, plant functions ${ }^{[12]}$ and the response of plants to environmental changes are often correlated with soil resources ${ }^{[13-15]}$. Thus, a precise prediction of the availability of soil resources could help us understand some important ecological processes in terrestrial ecosystems.

The correlations among soil properties can predicate the availability of soil resources, and most of these correlations have been assessed. For example, the scaling of soil organic carbon (OC) to nitrogen $(\mathrm{N})$ (C: $\mathrm{N}$ ratio) can effectively indicate the mineralization of soil $\mathrm{OC}$ and $\mathrm{N}$ and, thus, their availabilities to soil

Received date: 2019-07-26 Accepted date: 2020-03-10

Biographies: Baicheng Xie, Master, Senior Engineer, research interests: agrometeorology and ecological environment, Email: xbcyyhn@163.com; Chunxia Zhang, Master, Associate Professor, research interests: environmental protection and food science, Email: 46327304@qq.com; Yingge Xie, PhD, Associate Professor, research interests: environmental biophysics and soil science, Email: xieyingge1976@nwafu.edu.cn.

*Correspondence: Guodong Wang, PhD, Professor, research interests: environmental biophysics and soil science. College of Science, Northwest A\&F University, Yangling 712100, Shaanxi, China. Tel: +86-29-87092357, Email: gdwang211@aliyun.com. microbes and plants in different ecosystems ${ }^{[16,17]}$. The C:N ratios are generally higher in forest soil than in cultivated soil ${ }^{[18]}$. The cation exchange capacity (CEC) of soil can describe the availability of nutrients for plant growth, and soil OC is often used to predicate soil CEC due to the high dependence of soil CEC on soil OC ${ }^{[19,20]}$. Although the relationships between soil properties have been reported at the slope ${ }^{[21]}$, site ${ }^{[22]}$ and regional scales ${ }^{[23]}$, studies are relatively limited at the global scale. Furthermore, whether and how these relationships depend on different continents and land uses remain less studied, hindering a precise understanding of the availability of soil resources and ecological processes.

Global convergences have been observed for many plant traits and ecological processes. For example, Reich et al. ${ }^{[12]}$ found a global convergence in the functioning of plants across biomes. $\mathrm{Xu}$ et al. ${ }^{[24]}$ established convergence in the relationship of exchanges of $\mathrm{CO}_{2}$ and $\mathrm{N}_{2} \mathrm{O}$ between the soil and atmosphere within terrestrial ecosystems. Mahecha et al. ${ }^{[25]}$ reported a global convergence in the temperature sensitivity of respiration at the ecosystem level. Therefore, a global convergence in the correlations was hypothesized to exist among major soil properties, because the traits and functioning of plants, emissions of $\mathrm{CO}_{2}$ and $\mathrm{N}_{2} \mathrm{O}$ from the soil and ecosystem respiration are closely related to soil resources.

To test the hypothesis, the correlations among major soil properties were examined, including OC, total $\mathrm{N}$ (TN) and sand content, $\mathrm{pH}$, electrical conductivity (ECE) and CEC at a global scale by analyzing a global soil dataset. The effects of continent and land use type on these correlations were also tested. The objective of this study was to determine whether the correlations among soil properties were convergent and whether such correlations varied among continents and land use types. 


\section{Materials and methods}

\subsection{Description of the dataset}

The dataset analyzed in this study was derived from a global soil database (ISRIC-WISE-Global Soil Profile Data (ver. 3.1)) (Figure 1) ${ }^{[26]}$. This database contains 10253 soil profiles from 149 countries. Only 10 profiles were sampled from Antarctica; thus, this continent was excluded from the dataset. Soil depth varied with soil profile in the database; therefore, we used averaged values of soil properties in the upper $35 \mathrm{~cm}$. The soils in this layer are important for most biogeochemical processes and plant growth. It excluded an additional 355 profiles in which the top sampling depths were deeper than $35 \mathrm{~cm}$. In total, 9888 profiles in the dataset were used in this study. Of these, 3822 provided accurate descriptions of land use.

These soil profiles were classified into four land use types: cultivated land, forest, grassland and preserved land. Soil OC, TN and sand content, $\mathrm{pH}, \mathrm{ECE}$ and CEC were selected as the major properties for the current analysis because these variables can indicate the physicochemical properties and fertility of soils. The soil OC content and CEC are assumed to depend on the clay content ${ }^{[19,20]}$, but the analysis showed that they depended more on the sand content; as a result, sand content rather than clay content was chosen in this study. The global distributions of the profiles are shown in Figure 1. The basic conditions of the dataset used in this study are shown in Table 1.



Figure 1 Global distribution of geo-referenced soil profiles in WISE3 ${ }^{[26]}$

Table 1 Basic conditions of the dataset

\begin{tabular}{|c|c|c|c|c|c|c|}
\hline \multirow{2}{*}{\multicolumn{2}{|c|}{$\begin{array}{c}\text { Total profile } \\
\text { numbers }\end{array}$}} & \multicolumn{5}{|c|}{ Number of paired soil properties } \\
\hline & & OC-TN & OC-CEC & pH-ECE & SAND-OC & SAND-CEC \\
\hline \multicolumn{7}{|c|}{ Across the whole dataset } \\
\hline & 9888 & 6724 & 9030 & 7145 & 9212 & 8943 \\
\hline \multicolumn{7}{|c|}{ Within continents } \\
\hline $\mathrm{AF}$ & 4063 & 2535 & 3719 & 3012 & 3736 & 3721 \\
\hline AS & 1795 & 1014 & 1644 & 1248 & 1738 & 1663 \\
\hline AU & 208 & 159 & 176 & 184 & 177 & 180 \\
\hline EU & 1231 & 977 & 1070 & 721 & 1127 & 1020 \\
\hline NA & 834 & 599 & 737 & 519 & 765 & 714 \\
\hline SA & 1757 & 1440 & 1684 & 1461 & 1669 & 1645 \\
\hline \multicolumn{7}{|c|}{ Within land use types } \\
\hline $\mathrm{C}$ & 1780 & 1191 & 1648 & 1296 & 1708 & 1642 \\
\hline F & 342 & 257 & 312 & 295 & 319 & 304 \\
\hline G & 1135 & 554 & 1044 & 881 & 1030 & 1050 \\
\hline $\mathrm{PN}$ & 565 & 460 & 536 & 469 & 542 & 523 \\
\hline
\end{tabular}

Note: OC: organic carbon; TN: total nitrogen; SAND: sand content; CEC: cation exchange capacity; ECE: electrical conductivity; AF: Africa; AS: Asia; AU: Oceania; EU: Europe; NA: North America; SA: South America; C: cultivated land; F: forest; G: grassland; PN: preserved land.

\subsection{Statistical analysis}

A two-way analysis of variance was used to test the variations in soil properties among continents and land use types. A simple regression analysis was conducted to establish the correlation of soil OC content and CEC with soil sand content, of soil TN content and CEC with soil OC content and of soil ECE with soil pH. These correlations were tested both among and within continents and land use types. The slopes of these correlations among continents and land use types were examined using SMATR version 2 . The variance and regression analyses were conducted using SAS 9.0.

\section{Results}

The global analysis indicated that soil properties varied significantly among continents and land use types (Figure 2). Within continents, soils from Europe (EU), Oceania (AU) and North America (NA) had higher OC and TN contents and CECs $(p<0.01)$, while soils from NA and Asia (AS) had higher $\mathrm{pH}$ values $(p<0.01)$. Soils from Africa (AF) and AU had higher sand contents $(p<0.01)$, while the soils from AS had higher ECEs $(p<0.01)$. Within land use types, the soil OC and TN contents were higher in forests but lower in cultivated land. Conversely, soil $\mathrm{pH}$ was higher in cultivated land but lower in forests. Forests, cultivated land and grassland had higher soil CECs than did preserved land. Unlike the observation that $\mathrm{pH}$ and soil OC, TN and sand content in forests were similar to those of preserved land, ECE was significantly higher in forests and significantly lower in preserved land. Additionally, the variations in soil properties among land use types depended on the continent (Figure 3). For example, higher OC and TN contents were observed in cultivated soils from AU but in forest and grassland soils from EU. Higher $\mathrm{pH}$ values were observed in cultivated soils from EU, in forests from NA and in grassland from AS. These results suggest that 
differences among continents and land use types play important


roles in influencing the global patterns of soil properties.
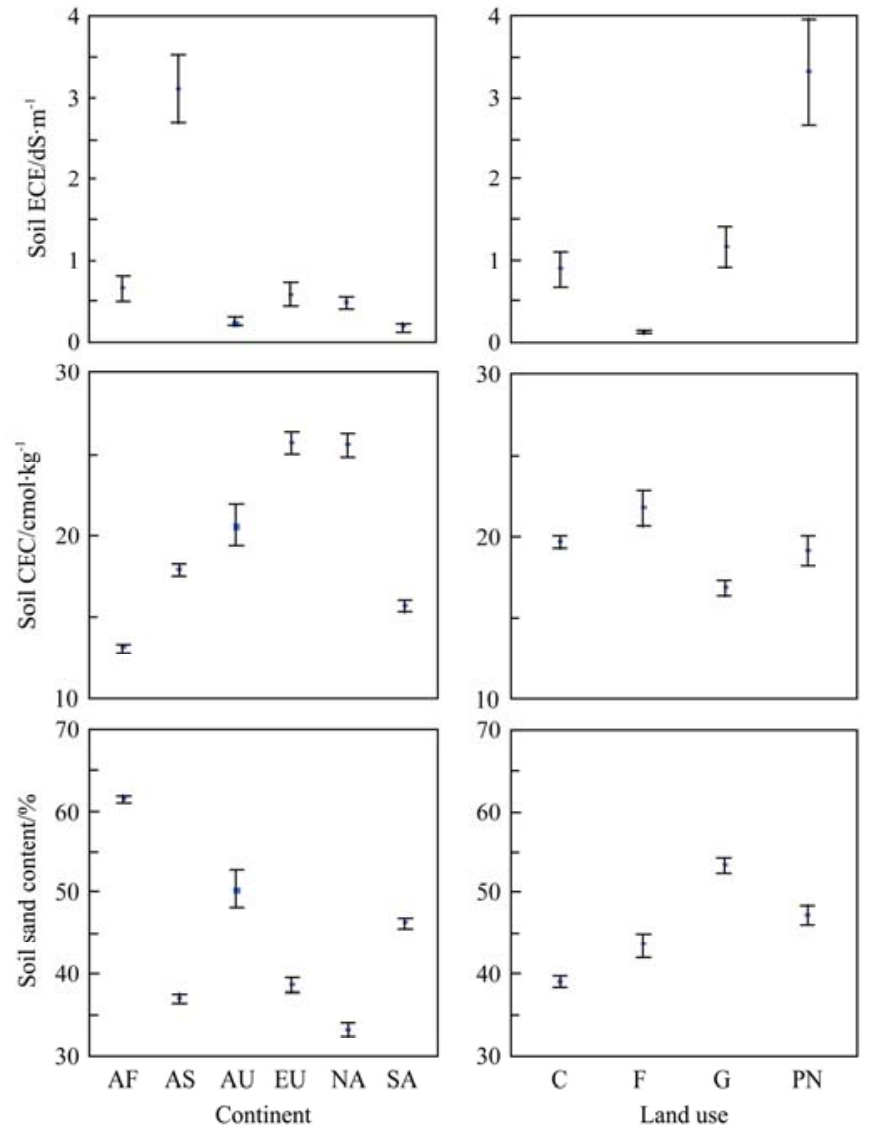

OC: organic carbon; TN: total nitrogen; CEC: cation exchange capacity; ECE: electrical conductivity. AF: Africa; AS: Asia; AU: Oceania; EU: Europe; NA: North America; SA: South America; C: cultivated land; F: forest; G: grassland; PN: preserved land.

Figure 2 Variations in soil properties with continents and land use types
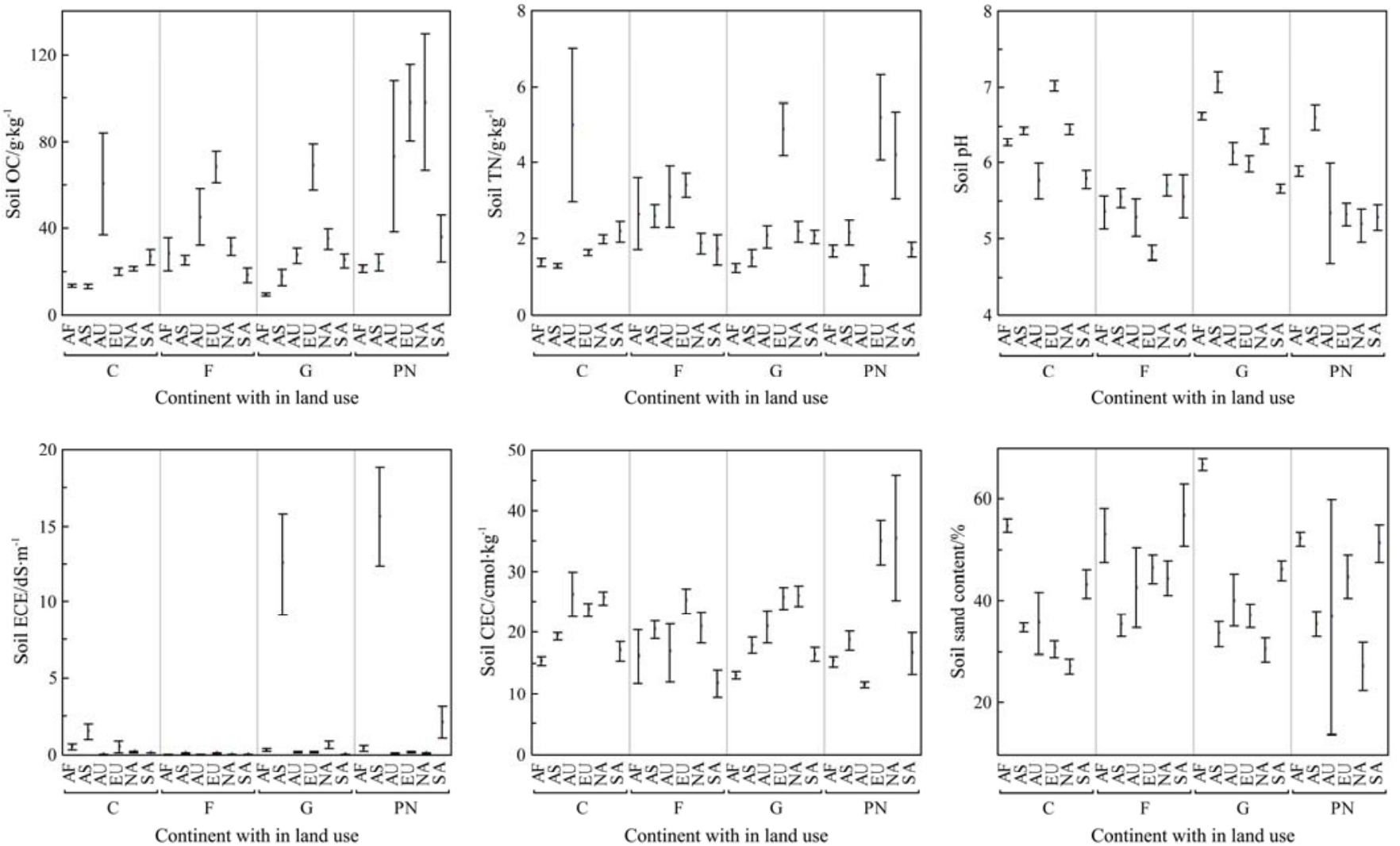

OC: organic carbon; TN: total nitrogen; CEC: cation exchange capacity; ECE: electrical conductivity; AF: Africa; AS: Asia; AU: Oceania;

EU: Europe; NA: North America; SA: South America; C: cultivated land; F: forest; G: grassland; PN: preserved land.

Figure 3 Effects of continents on soil properties within land use types 
Soil properties were significantly correlated among the continents and land use types (Figure 4). ECE increased significantly with increasing $\mathrm{pH}$; TN content and CEC increased significantly with increasing OC content; OC content and CEC decreased significantly with increasing sand content. The correlations between paired soil properties were consistent among
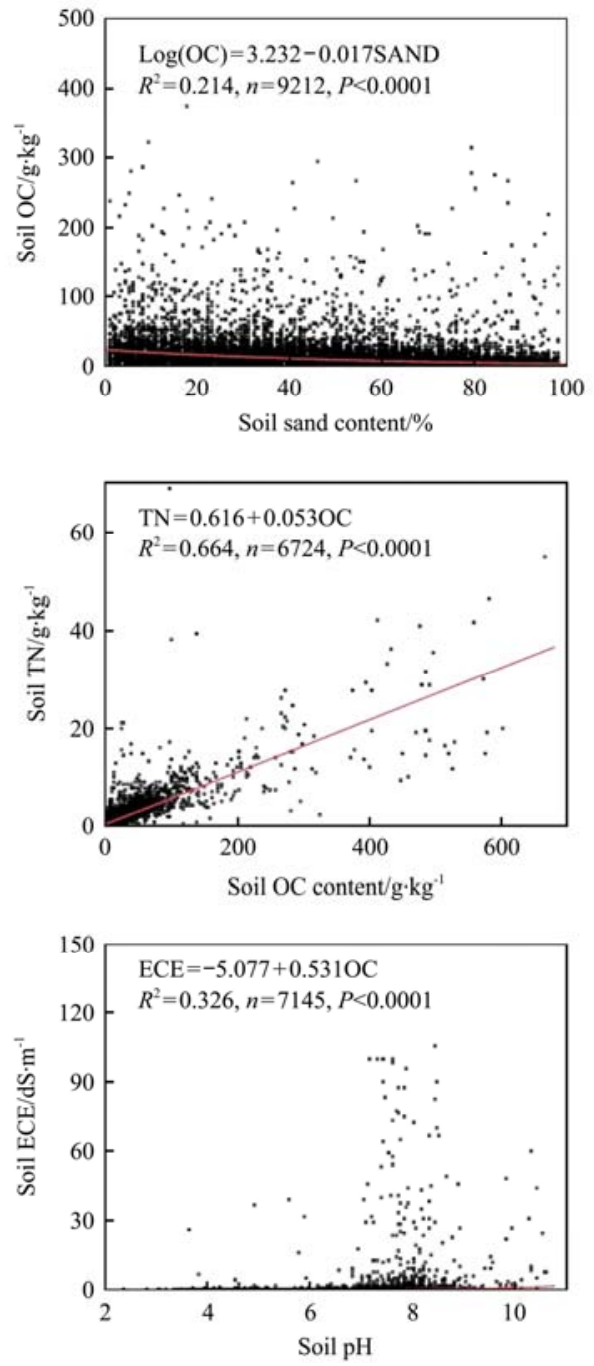

continents and land use types (Tables 2 and 3), indicating global convergences in the correlations. These global convergences suggest that, at the global scale, ECE was mainly determined by $\mathrm{pH}$, CEC was influenced by both OC and sand content, and TN content was determined by OC content, which in turn depended on sand content.


OC: organic carbon; CEC: soil cation exchange capacity; TN: total nitrogen; ECE: soil electrical conductivity.

Figure 4 Correlations among soil properties across continents and land use types

Even though consistent relationships between paired soil properties occurred in all continents and land use types, the slopes of specific relationships varied significantly with the continent (Table 2) and land use type (Table 3). Within continents, significantly higher regression slopes of the relationships of OC content and CEC to sand content were observed in EU, lower slopes were observed for these two relationships in AF, and the slopes for the other continents $(-0.011$ to -0.016 and -0.019 to -0.021 , respectively) were similar to the slopes observed on the global scale ( -0.017 and -0.022 , respectively), suggesting that OC content and CEC were highly dependent on sand content in EU but less dependent in AF. The TN content and CEC depended strongly on the OC content in AF and SA, while the ECE depended strongly on the $\mathrm{pH}$ in NA and AS.

Higher regression slopes were found for the relationships of OC content and CEC to sand content were observed in forests, while lower slopes for these two correlations were observed in grassland. ECE depended strongly on $\mathrm{pH}$ in preserved land but weakly in forests. The TN content and CEC depended more strongly on OC content in cultivated land than in forest and grassland.

The sampling profiles in South America (SA), AF and AS accounted for $77 \%$ of the total global dataset; thus, the correlations among soil properties within land use types for these three continents were examined further. The correlations within land use types varied significantly with the continent (Table 4). Most relationships of OC content and CEC to sand content had higher regression slopes in AS but lower slopes in AF for the four land use types. The regression slope of the relationship of the TN content to OC content was higher in AF than in AS for cultivated land and forest but higher in AS than in AF for grassland. The dependence of the CEC on the OC content was higher in SA for cultivated land, forest and preserved land and was higher in AF for grassland. These results suggest nonconvergence in the regression slope of the relationship between paired soil properties within continents and land use types, indicating variation in the dependence of certain soil properties on other properties within continents and land use types. 
Table 2 Correlations among soil properties within continents

\begin{tabular}{|c|c|c|c|c|c|c|c|}
\hline \multirow{2}{*}{ Continent } & \multicolumn{2}{|c|}{ Intercept } & \multicolumn{2}{|c|}{ Slope } & \multirow{2}{*}{$R^{2}$} & \multirow{2}{*}{$n$} & \multirow{2}{*}{$p$} \\
\hline & Estimate & Std Err & Estimate & Std Err & & & \\
\hline \multicolumn{8}{|c|}{$\log (\mathrm{OC})=a+b \times \mathrm{SAND}$} \\
\hline Africa & 3.36 & 0.03 & $-0.022 \mathrm{c}$ & 0.001 & 0.32 & 3736 & $<0.001$ \\
\hline Asia & 2.70 & 0.04 & $-0.011 \mathrm{~b}$ & 0.001 & 0.08 & 1738 & $<0.001$ \\
\hline Oceania & 3.84 & 0.11 & $-0.014 \mathrm{~b}$ & 0.002 & 0.22 & 177 & $<0.001$ \\
\hline Europe & 3.18 & 0.05 & $-0.002 \mathrm{a}$ & 0.001 & 0.01 & 1127 & 0.010 \\
\hline North America & 3.33 & 0.05 & $-0.012 \mathrm{~b}$ & 0.001 & 0.12 & 765 & $<0.001$ \\
\hline South America & 3.36 & 0.04 & -0.016 bc & 0.001 & 0.21 & 1669 & $<0.001$ \\
\hline \multicolumn{8}{|c|}{$\log (\mathrm{CEC})=a+b \times \mathrm{SAND}$} \\
\hline Africa & 3.84 & 0.03 & $-0.027 \mathrm{c}$ & 0.000 & 0.57 & 3721 & $<0.001$ \\
\hline Asia & 3.33 & 0.03 & $-0.021 \mathrm{~b}$ & 0.001 & 0.38 & 1663 & $<0.001$ \\
\hline Oceania & 3.67 & 0.10 & $-0.021 \mathrm{~b}$ & 0.002 & 0.43 & 180 & $<0.001$ \\
\hline Europe & 3.40 & 0.04 & -0.012 a & 0.001 & 0.21 & 1020 & $<0.001$ \\
\hline North America & 3.58 & 0.04 & $-0.019 \mathrm{~b}$ & 0.001 & 0.35 & 714 & $<0.001$ \\
\hline South America & 3.28 & 0.04 & $-0.020 \mathrm{~b}$ & 0.001 & 0.35 & 1645 & $<0.001$ \\
\hline \multicolumn{8}{|c|}{$\log (\mathrm{ECE})=a-b \times \mathrm{pH}$} \\
\hline Africa & -5.29 & 0.10 & $0.533 \mathrm{~b}$ & 0.015 & 0.34 & 2350 & $<0.001$ \\
\hline Asia & -5.12 & 0.22 & $0.582 \mathrm{~b}$ & 0.031 & 0.25 & 1040 & $<0.001$ \\
\hline Oceania & -3.34 & 0.60 & $0.202 \mathrm{~d}$ & 0.099 & 0.03 & 151 & 0.043 \\
\hline Europe & -4.44 & 0.15 & 0.450 c & 0.026 & 0.29 & 702 & $<0.001$ \\
\hline North America & -5.73 & 0.24 & 0.650 a & 0.037 & 0.41 & 449 & $<0.001$ \\
\hline South America & -3.51 & 0.10 & $0.240 \mathrm{~d}$ & 0.018 & 0.15 & 1018 & $<0.001$ \\
\hline \multicolumn{8}{|c|}{$T N=a+b \times O C$} \\
\hline Africa & 0.29 & 0.03 & 0.063 a & 0.001 & 0.59 & 2535 & $<0.001$ \\
\hline Asia & 0.77 & 0.08 & $0.050 \mathrm{~b}$ & 0.003 & 0.29 & 1014 & $<0.001$ \\
\hline Oceania & 0.68 & 0.18 & $0.048 \mathrm{~b}$ & 0.002 & 0.71 & 159 & $<0.001$ \\
\hline Europe & 0.95 & 0.10 & $0.051 \mathrm{~b}$ & 0.001 & 0.74 & 977 & $<0.001$ \\
\hline North America & 0.95 & 0.07 & 0.043 c & 0.001 & 0.72 & 599 & $<0.001$ \\
\hline South America & 0.42 & 0.05 & 0.068 a & 0.001 & 0.71 & 1440 & $<0.001$ \\
\hline \multicolumn{8}{|c|}{$\mathrm{CEC}=a+b \times \mathrm{OC}$} \\
\hline Africa & 9.21 & 0.26 & 0.309 a & 0.012 & 0.16 & 3719 & $<0.001$ \\
\hline Asia & 14.41 & 0.42 & 0.208 c & 0.015 & 0.11 & 1644 & $<0.001$ \\
\hline Oceania & 14.42 & 1.45 & 0.191 c & 0.025 & 0.25 & 176 & $<0.001$ \\
\hline Europe & 18.08 & 0.57 & 0.171 с & 0.006 & 0.42 & 1070 & $<0.001$ \\
\hline North America & 17.77 & 0.68 & 0.245 bc & 0.011 & 0.40 & 737 & $<0.001$ \\
\hline South America & 9.49 & 0.32 & $0.265 \mathrm{~b}$ & 0.007 & 0.44 & 1684 & $<0.001$ \\
\hline
\end{tabular}

Note: OC: organic carbon; TN: total nitrogen; SAND: sand content; CEC: cation exchange capacity; ECE: electrical conductivity. Slopes with different lower case letters within the same relationship were significant at $p<0.01$.
Table 3 Correlations among soil properties within land use types

\begin{tabular}{|c|c|c|c|c|c|c|c|}
\hline \multirow{2}{*}{ Land use } & \multicolumn{2}{|c|}{ Intercept } & \multicolumn{2}{|c|}{ Slope } & \multirow{2}{*}{$R^{2}$} & \multirow{2}{*}{$n$} & \multirow{2}{*}{$p$} \\
\hline & Estimate & Std Err & Estimate & Std Err & & & \\
\hline \multicolumn{8}{|c|}{$\log (\mathrm{OC})=a+b \times$ SAND } \\
\hline Cultivated land & 2.93 & 0.03 & $-0.013 \mathrm{~b}$ & 0.001 & 0.18 & 1708 & $<0.001$ \\
\hline Forest & 3.47 & 0.11 & -0.006 a & 0.002 & 0.03 & 319 & 0.007 \\
\hline Grassland & 3.64 & 0.05 & -0.026 c & 0.001 & 0.45 & 1030 & $<0.001$ \\
\hline Preserved land & 3.29 & 0.09 & $-0.013 \mathrm{~b}$ & 0.002 & 0.10 & 532 & $<0.001$ \\
\hline \multicolumn{8}{|c|}{$\log (\mathrm{CEC})=a+b \times$ SAND } \\
\hline Cultivated land & 3.52 & 0.03 & $-0.023 \mathrm{~b}$ & 0.001 & 0.49 & 1642 & $<0.001$ \\
\hline Forest & 3.29 & 0.09 & -0.014 a & 0.002 & 0.16 & 304 & $<0.001$ \\
\hline Grassland & 3.72 & 0.04 & $-0.025 \mathrm{~b}$ & 0.001 & 0.61 & 1050 & $<0.001$ \\
\hline Preserved land & 3.44 & 0.06 & $-0.021 \mathrm{~b}$ & 0.001 & 0.40 & 515 & $<0.001$ \\
\hline \multicolumn{8}{|c|}{$\log (\mathrm{ECE})=a-b \times \mathrm{pH}$} \\
\hline Cultivated land & -5.34 & 0.16 & $0.570 \mathrm{~b}$ & 0.024 & 0.35 & 1043 & $<0.001$ \\
\hline Forest & -3.22 & 0.16 & $0.208 \mathrm{c}$ & 0.031 & 0.16 & 241 & $<0.001$ \\
\hline Grassland & -5.55 & 0.19 & $0.591 \mathrm{~b}$ & 0.030 & 0.32 & 792 & $<0.001$ \\
\hline Preserved land & -6.81 & 0.34 & 0.911 a & 0.055 & 0.47 & 311 & $<0.001$ \\
\hline \multicolumn{8}{|c|}{$\mathrm{TN}=a+b \times \mathrm{OC}$} \\
\hline Cultivated land & 0.58 & 0.03 & 0.055 a & 0.001 & 0.71 & 1191 & $<0.001$ \\
\hline Forest & 1.01 & 0.11 & $0.038 \mathrm{~b}$ & 0.001 & 0.72 & 257 & $<0.001$ \\
\hline Grassland & 0.67 & 0.07 & $0.052 \mathrm{a}$ & 0.001 & 0.84 & 554 & $<0.001$ \\
\hline Preserved land & 0.61 & 0.10 & $0.045 \mathrm{~b}$ & 0.001 & 0.76 & 450 & $<0.001$ \\
\hline \multicolumn{8}{|c|}{$\mathrm{CEC}=a+b \times \mathrm{OC}$} \\
\hline Cultivated land & 14.40 & 0.47 & 0.315 a & 0.018 & 0.16 & 1648 & $<0.001$ \\
\hline Forest & 11.75 & 1.01 & $0.234 \mathrm{~b}$ & 0.014 & 0.47 & 312 & $<0.001$ \\
\hline Grassland & 12.88 & 0.49 & 0.199 c & 0.009 & 0.30 & 1044 & $<0.001$ \\
\hline Preserved land & 11.38 & 0.70 & 0.211 bc & 0.008 & 0.55 & 528 & $<0.001$ \\
\hline
\end{tabular}

Table 4 Correlations among soil properties within continents and land use types

\begin{tabular}{|c|c|c|c|c|c|c|c|c|}
\hline \multirow{2}{*}{ Land use } & \multirow{2}{*}{ Continent } & \multicolumn{2}{|c|}{ Intercept } & \multicolumn{2}{|c|}{ Slope } & \multirow{2}{*}{$R^{2}$} & \multirow{2}{*}{$n$} & \multirow{2}{*}{$p$} \\
\hline & & Estimate & Std Err & Estimate & Std Err & & & \\
\hline \multicolumn{9}{|c|}{$\log (\mathrm{OC})=a+b \times \mathrm{SAND}$} \\
\hline Cultivated land & Africa & 3.25 & 0.08 & $-0.019 \mathrm{~b}$ & 0.001 & 0.31 & 441 & $<0.001$ \\
\hline Cultivated land & Asia & 2.57 & 0.05 & $-0.010 \mathrm{a}$ & 0.001 & 0.11 & 718 & $<0.001$ \\
\hline Cultivated land & South America & 3.72 & 0.17 & $-0.020 \mathrm{~b}$ & 0.003 & 0.29 & 84 & $<0.001$ \\
\hline Forest & Africa & 5.08 & 0.43 & $-0.041 \mathrm{~d}$ & 0.008 & 0.70 & 15 & 0.001 \\
\hline Forest & Asia & 3.32 & 0.18 & -0.012 a & 0.004 & 0.08 & 94 & 0.006 \\
\hline Forest & South America & 3.51 & 0.48 & $-0.016 \mathrm{ab}$ & 0.008 & 0.20 & 17 & 0.074 \\
\hline Grassland & Africa & 3.53 & 0.08 & $-0.028 \mathrm{c}$ & 0.001 & 0.54 & 532 & $<0.001$ \\
\hline Grassland & Asia & 2.65 & 0.19 & -0.008 a & 0.005 & 0.04 & 75 & 0.094 \\
\hline Grassland & South America & 3.55 & 0.11 & $-0.017 \mathrm{ab}$ & 0.002 & 0.30 & 181 & $<0.001$ \\
\hline Preserved land & Africa & 3.24 & 0.11 & $-0.014 \mathrm{ab}$ & 0.002 & 0.14 & 309 & $<0.001$ \\
\hline Preserved land & Asia & 2.93 & 0.24 & -0.013 a & 0.006 & 0.058 & 91 & $<0.001$ \\
\hline Preserved land & South America & 3.81 & 0.27 & $-0.021 \mathrm{~b}$ & 0.005 & 0.30 & 51 & $<0.001$ \\
\hline
\end{tabular}




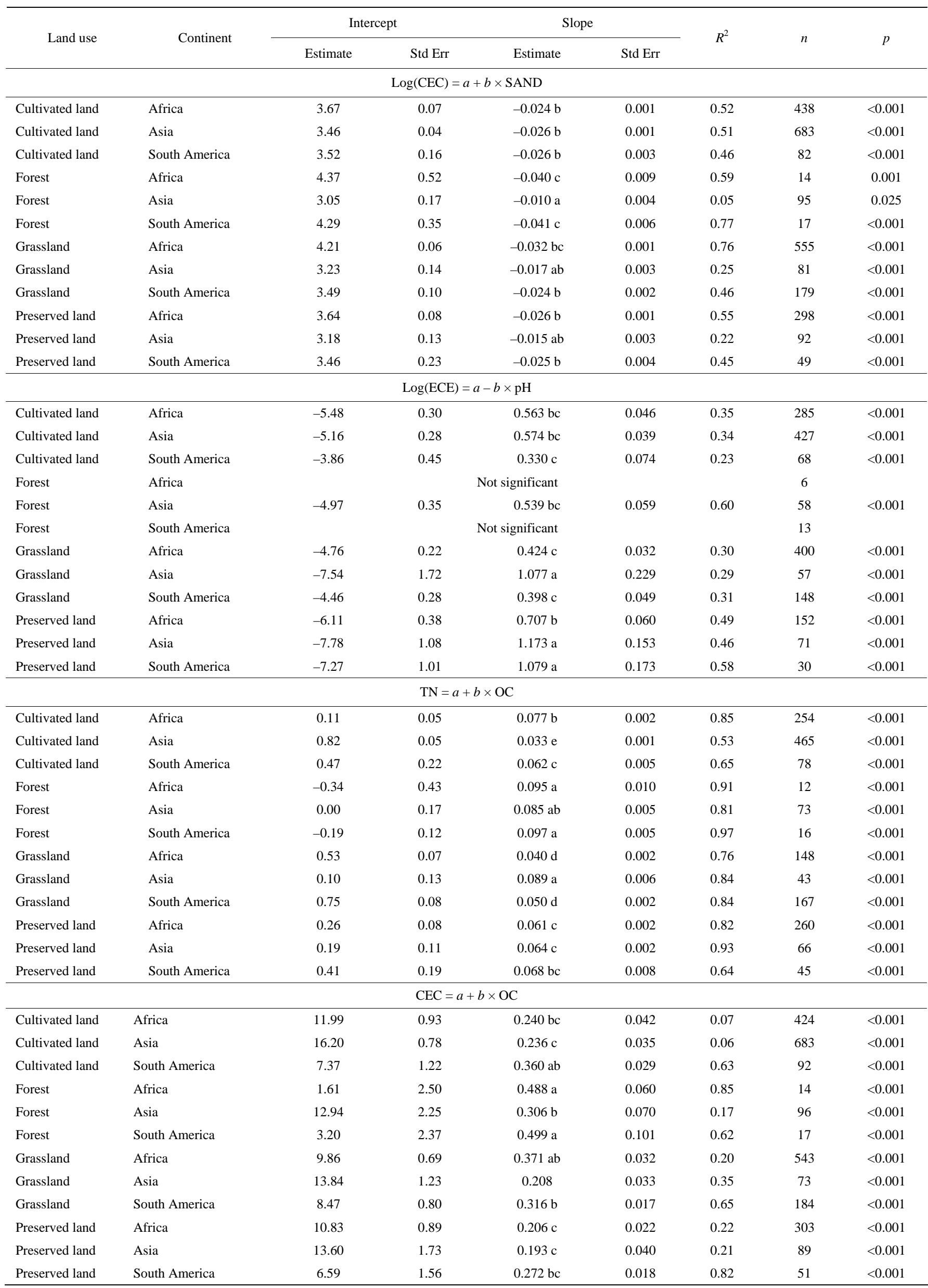

Note: OC: organic carbon; TN: total nitrogen; SAND: sand content; CEC: cation exchange capacity; ECE: electrical conductivity. Slopes with different lower case letters within same relationship were significantly at $p<0.01$. 


\section{Discussions}

As expected, the global analysis found similar correlations between paired soil properties in all continents and land use types, demonstrating global convergences in correlations among soil properties. The correlations among soil sand, OC and TN contents and CEC have been well established on relatively small scales $^{[16,17,19,20]}$. Correlations between $\mathrm{pH}$ and ECE, however, are variable but have been less commonly reported in the literature. For example, Johnson et al. ${ }^{[27]}$ and Corwin et al. ${ }^{[28]}$ observed positive correlations between $\mathrm{pH}$ and ECE in the pasture, forest and cultivated soils, while Shi et al. ${ }^{[29]}$ and Akahane et al. ${ }^{[30]}$ suggested a negative correlation in cultivated soils. A consistent positive correlation was found among six continents and four land use types, suggesting a fundamental positive scaling of $\mathrm{pH}$ to ECE. A possible explanation for this positive correlation might be the high salinities (and thus high ECEs) found in soils with high $\mathrm{pH}$.

The analysis suggests a global generality of relationships among soil properties. This global convergence is mainly due to the concurrence of soil properties regardless of location or land use type. High sand content often leads to high soil permeability and mineralization rates of soil organic matter ${ }^{[31,32]}$, low stability of soil aggregates $^{[33]}$ and fewer cation-exchange sites on soil particles ${ }^{[32]}$, which decrease the OC and CEC. Most $\mathrm{N}$ in soils is found in organic matter, explaining the significant positive correlation between the $\mathrm{OC}$ and $\mathrm{N}$ contents in various ecosystems ${ }^{[34]}$. More organic matter in the soil (thus a higher OC content) provides more surface area and exchange sites for cations in soil particles, resulting in higher CECs ${ }^{[35]}$.

Although the analysis found universal specific correlations between paired soil properties among continents and land use types, the regression slopes of the specific correlations varied significantly with the continent and land use type. These variations may be due to the significant differences in soil properties within continents and land use types. On a global scale, the $\mathrm{OC}$ and $\mathrm{N}$ contents were significantly higher in soils from temperate regions than in soils from tropical regions ${ }^{[36]}$. Thus, the $\mathrm{OC}$ and TN contents were thus higher in $\mathrm{EU}, \mathrm{AU}$ and NA than in $\mathrm{AS}, \mathrm{AF}$ and SA $(p<0.05)$. Land in $\mathrm{AF}$ and $\mathrm{AU}$ was highly desertified relative to other continents ${ }^{[37]}$. The sand contents were therefore higher in the soils from AF and AU. As predicted by the correlations that CEC significantly increased with increasing OC and decreasing sand content, the CEC values were larger in NA and EU than in $\mathrm{AF}$ and SA. Soil $\mathrm{pH}$ is largely controlled by precipitation because high rainfall leaches the base/primary nutrients and cations from the soil and thereby decreases $\mathrm{pH}$. Under these global patterns of soil properties among continents, the higher sand and lower OC contents and lower CEC values in AF soils corresponded to the lower dependence of OC content and CEC on sand content (lower regression slopes of the relationships between sand content and $\mathrm{OC}$ content and between sand content and CEC), while the lower sand content and higher OC content and CEC in EU soils resulted in the higher dependence of OC content and CEC on sand content (higher regression slopes). The significantly lower OC content in AF resulted in the higher scaling of OC to TN and CEC, while the higher OC content in EU resulted in lower scaling. ECE was significantly higher in AS than in other continents, resulting in a significantly higher regression slope for the relationship of ECE to $\mathrm{pH}$.

Within types of land use, the OC and $\mathrm{N}$ accumulated in soils of forests and preserved land but were lost in cultivated soil ${ }^{[38,39]}$, resulting in higher OC and TN contents in forests and preserved land but lower contents in cultivated land. The accumulation of organic matter in soil often decreases soil $\mathrm{pH}^{[40]}$. The analysis of the global dataset showed significant decreases in $\mathrm{pH}$ with increasing OC content (Figure 5). Thus, the soil $\mathrm{pH}$ in forests and preserved land is significantly lower than that in other types of land use. The soil of cultivated land was globally well developed compared to the soil of undisturbed land, and the sand content was significantly lower. The lower sand content in cultivated soil and higher OC content in forest soil led to significantly higher CECs in cultivated land and forests. Based on the global pattern of soil properties with land use types, the lower sand and higher OC contents and the higher CECs in forest soil led to the relatively higher dependence of soil OC content and CEC on sand content. The accumulation of OC is generally greater than the accumulation of $\mathrm{N}$ in forest soil ${ }^{[38,41]}$, explaining the relatively lower dependence of TN content on OC content. The lower OC content and higher CEC in cultivated soil led to the highest regression slope for the relationship of CEC to OC content. Similarly, the higher ECE and lower $\mathrm{pH}$ in the soil of preserved land led to the highest slope for the relationship of ECE to $\mathrm{pH}$. Taken together, the convergence in the correlation between paired soil properties among continents and land use types, and the different regression slope for specific correlations within continents and land use types, demonstrate a global dependence of OC content and CEC on sand content, of TN content and CEC on OC content and of ECE on pH.

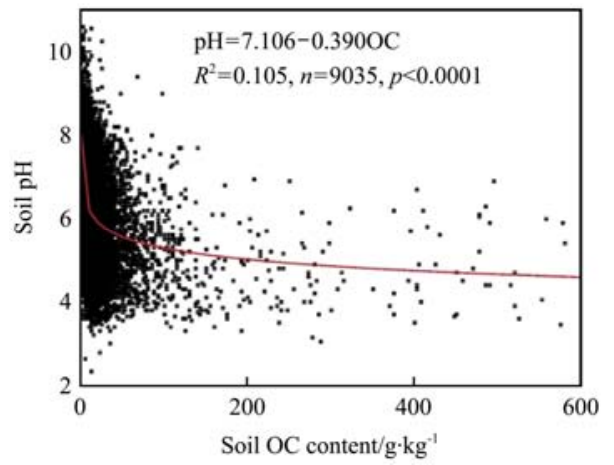

Figure 5 Correlation between soil OC and soil pH across continents and land use types. Soil $\mathrm{pH}$ decreased significantly with soil OC content

Sand, OC and TN contents, pH, CEC and ECE directly affect the availability of soil water and nutrients to plants and soil microbes ${ }^{[42,43]}$ and the tolerance of plants and soil microbes to soil contamination and degradation ${ }^{[44,45]}$. Thus, these properties affect the responses of plant growth, functional traits and biogeochemical processes to the availability of soil resources and to changes in soil quality. The evidence presented in this study for the global convergence of correlations among soil properties imply a general scaling of soil resources to some ecosystem traits, such as plant function and biogeochemical cycles. The consistent dependence of TN content on OC content indicates a global convergence in the availability of soil $\mathrm{N}$ to plants, which supports the global convergences in foliar $\mathrm{N}$ content and foliar traits ${ }^{[8,9]}$ and thus in plant function ${ }^{[12]}$. The consistent correlations between sand and OC contents and between OC and TN contents indicate a convergence in the availability of soil OC, which partly contributes to the global convergence in the temperature sensitivity of ecosystem respiration ${ }^{[25]}$. The universal correlation between OC and TN contents may be related to the convergence in the correlation between the emissions of soil $\mathrm{CO}_{2}$ and $\mathrm{N}_{2} \mathrm{O}$ observed by 
$\mathrm{Xu}$ et al. ${ }^{[24]}$. Additionally, the convergence in the dependence of ECE on $\mathrm{pH}$ has implications for agricultural production. ECE is a useful index for estimating crop yield ${ }^{[46,47]}$. An increase in ECE will decrease crop yield ${ }^{[46]}$. The application of fertilizer, though, often decreases soil $\mathrm{pH}^{[48]}$, which would decrease ECE according to the correlation that ECE increases with $\mathrm{pH}$. The effects of fertilization on crop yield would thus be higher than expected on a global scale.

The current results demonstrate that the dependence of certain soil properties on other properties varied significantly among continents and land use types, which can partly explain the variations in ecosystem traits and biogeochemical properties within continents and land use types. The higher scaling of OC to TN contents in $\mathrm{AF}$ and $\mathrm{SA}$, but the lower scaling in NA, indicates a higher availability of soil $\mathrm{N}$ in AF and SA but a lower availability in NA. Therefore, it is predicted that foliar $\mathrm{N}$ should be higher in AS and SA than in NA because foliar $\mathrm{N}$ is positively correlated with the availability of soil $\mathrm{N}$ and with the $\mathrm{N}: \mathrm{C}$ ratio ${ }^{[8,9,49]}$. This prediction is supported by the global patterns of foliar litter $\mathrm{N}$ in woody plants ${ }^{[50]}$. Kang et al. ${ }^{[50]}$ reported higher foliar litter $\mathrm{N}$ in woody plants in AF and SA but lower foliar litter $\mathrm{N}$ in AS, which is consistent with the observation that the scaling of OC to $\mathrm{N}$ contents in forest soil was higher in AF and SA than in AS. The higher scaling of OC to TN contents (lower C:N ratio) in AF and SA can also lead to the rapid turnover of soil OC and thus to the loss of soil OC because the lower $\mathrm{C}: \mathrm{N}$ ratio accelerates the mineralization of soil organic matter ${ }^{[51]}$. It is therefore predicted that a higher level of soil respiration in AF and SA than in the other continents, which is consistent with the previous estimate that $\mathrm{AF}$ and SA had higher levels of total and heterotrophic soil respiration but lower $\mathrm{Q}_{10}$ values than other continents ${ }^{[52]}$.

The global analysis of this study showed that the dependence of soil TN to OC contents (higher C:N ratio) is significantly lower in soils of forests than in soils of cultivated land and grassland, indicating a faster turnover of OC and a higher level of soil respiration in forest soil than in soils of cultivated land and grassland. This result is consistent with the finding that, on a global scale, the turnover time of soil OC and soil respiration are higher in forests than in cultivated land and grassland ${ }^{[53]}$, and the $\mathrm{Q}_{10}$ is higher in cultivated land and grassland than in forests ${ }^{[52]}$.

\section{Conclusions}

In this study, the relationships among major soil properties on a global scale were examined, as well as the variation of these relationships with different continents and land uses. Consistent positive relationships were found between $\mathrm{OC}$ and $\mathrm{TN}$, between OC and CEC, and between $\mathrm{pH}$ and ECE, and negative relationships were found between sand and OC and between sand and CEC. However, the slope of these relationships differed between continents and land uses. Therefore, it is concluded that there was global convergence in the correlations among soil properties and the variations in the regression slopes of the relationships among continents and land use types. These results can have important implications for explaining the global patterns of biogeochemical processes and can provide some basis for linking soil resources and ecological processes on a global scale.

\section{Acknowledgements}

This research was supported by the National Key Research and Development Program of China (No. 2016YFD0300101), and the National Natural Science Foundation of China (31571560).

\section{[References]}

[1] Hamoud Y A, Guo X, Wang Z, Chen S, Rasool G. Effects of irrigation water regime, soil clay content and their combination on growth, yield, and water use efficiency of rice grown in South China. Int J Agric \& Biol Eng, 2018; 11(4): 144-155.

[2] LeBauer D S, Treseder K K. Nitrogen limitation of net primary productivity in terrestrial ecosystems is globally distributed. Ecology, 2008; 89(2): 371-379.

[3] Allison V J, Condron L M, Peltzer D A, Richardson S J, Turner B L. Changes in enzyme activities and soil microbial community composition along carbon and nutrient gradients at the Franz Josef chronosequence, New Zealand. Soil Biology \& Biochemistry, 2007; 39(7): 1770-1781.

[4] Sinsabaugh R L, Hill B H, Follstad Shah J J. Ecoenzymatic stoichiometry of microbial organic nutrient acquisition in soil and sediment. Nature, 2009; 462(7274): 795-798.

[5] Song L, Liu W, Wu H, Gao T, Hao W. Characteristics of soil nutrients and their relationship with soil microbial properties in Artemisia sacrorum communities in the loess hilly region. Int Agric \& Biol Eng, 2018; 11(4): 127-134.

[6] Joseph M C, Carl M, Noah F. Microbial nitrogen limitation increases decomposition. Ecology, 2007; 88(8): 2105-2113.

[7] Jackson R B, Mooney H A, Schulze E D. A global budget for fine root biomass, surface area, and nutrient contents. Proceedings of the National Academy of Science of the United States of America, 1997; 94(14): 7362-7366.

[8] Ordoñez J C, van Bodegom P M, Witte J-P M, Wright I J, Reich P B, Aerts R. A global study of relationships between leaf traits, climate and soil measures of nutrient fertility. Global Ecology and Biogeography, 2009; 18: 137-149.

[9] Reich P B, Oleksyn J. Global patterns of plant leaf N and P in relation to temperature and latitude. Proceedings of the National Academy of Science of the United States of America, 2004; 101: 11001-11006.

[10] Agren G I. Stoichiometry and nutrition of plant growth in natural communities. Annual Review of Ecology Evolution and Systematics, 2008; 39: 153-170.

[11] Yuan Z Y, Chen H Y, Reich P B. Global-scale latitudinal patterns of plant fine-root nitrogen and phosphorus. Nature Communications, 2001; 2: 344. doi:10.1038/ncomms1346.

[12] Reich P B, Walters M B, Ellsworth D S. From tropics to tundra: global convergence in plant functioning. Proceedings of the National Academy of Science of the United States of America, 1997; 94(25): 13730-13734.

[13] Field C B, Chapin F S, Matson P A, Mooney H A. Responses of terrestrial ecosystems to the changing atmosphere: a resource-based approach. Annual Review of Ecology Evolution and Systematics, 1992; 23(1): 201-235.

[14] Oren R. Soil fertility limits carbon sequestration by forest ecosystems in a $\mathrm{CO}_{2}$-enriched atmosphere. Nature, 2001; 411: 469-472.

[15] Rustad L E, Campbell J L, Marion G M, Norby R J, Mitchell M J, Hartley A E, et al. A meta-analysis of the response of soil respiration, net nitrogen mineralization, and aboveground plant growth to experimental ecosystem warming. Oecologia, 2001; 126(4): 543-562.

[16] Aitkenhead J A, McDowell W H. Soil C:N ratio as a predictor of annual DOC flux at local and global scales. Global Biogeochemical Cycles, 2000; 14(1): 127-138.

[17] Bengtsson G, Bengtson P, Månsson K F. Gross nitrogen mineralization-, immobilization-, and nitrification rates as a function of soil $\mathrm{C} / \mathrm{N}$ ratio and microbial activity. Soil Biology \& Biochemistry, 2003; 35(1): 143-154.

[18] Compton J E, Boone R D, Motzkin G, Foster D R. Soil carbon and nitrogen in a pine-oak sand plain in central Massachusetts: Role of vegetation and land-use history. Oecologia, 1998; 116(4): 536-542.

[19] Fu B, Qi Y B, Chang Q R. Impacts of revegetation management modes on soil properties and vegetation ecological restoration in degraded sandy grassland in farming-pastoral ecotone. Int J Agric \& Biol Eng, 2015; 8(1) 26-34.

[20] Seybold C A, Grossman R B, Reinsch T G. Predicting cation exchange capacity for soil survey using linear models. Soil Science Society of America Journal, 2005; 69(3): 856-863.

[21] Yao Y, Shao M, Fu X, Wang X, Wei X. Effects of shrubs on soil nutrients and enzymatic activities over a $0-100 \mathrm{~cm}$ soil profile in the desert-loess transition zone. Catena, 2019; 174: 362-370.

[22] Ping C L, Michaelson G J, Kane E S, Packee E C, Zaman N D. Carbon stores and biogeochemical properties of soils under Black Spruce Forest, 
Alaska. Soil Science Society of America Journal, 2010; 74(3): 969-978.

[23] Kumar S, La R. Mapping the organic carbon stocks of surface soils using local spatial interpolator. Journal of Environmental Monitoring, 2011; 13(11): 3128-3135.

[24] $\mathrm{Xu} \mathrm{X}$, Tian H, Hui D. Convergence in the relationship of $\mathrm{CO}_{2}$ and $\mathrm{N}_{2} \mathrm{O}$ exchanges between soil and atmosphere within terrestrial ecosystems. Global Change Biology, 2008; 14(7): 1651-1660.

[25] Mahecha M D, Reichstein M, Carvalhais N, Lasslop G, Lange H, Seneviratne S I, et al. Global convergence in the temperature sensitivity of respiration at ecosystem level. Science, 2010; 329(5993): 838-840.

[26] Batjes N H. ISRIC-WISE harmonized global soil profile dataset. ISRIC-World Soil Information, Wageningen, 2008.

[27] Johnson C K, Doran J, Duke H R, Wienhold B J, Eskridge K, Shanahan J F. Field-scale electrical conductivity mapping for delineating soil condition. Soil Science Society of America Journal, 2001; 65(6): 1829-1837.

[28] Corwin D L, Lesch S M, Oster J D, Kaffka S R. Monitoring management-induced spatio-temporal changes in soil quality through soil sampling directed by apparent electrical conductivity. Geoderma, 2006; 131(3-4): 369-387.

[29] Shi W M, Yao J, Yan F. Vegetable cultivation under greenhouse conditions leads to rapid accumulation of nutrients, acidification and salinity of soils and groundwater contamination in South-Eastern China. Nutrient Cycling in Agroecosystems, 2009; 83: 73-84.

[30] Akahane I, Makino T, Maejima Y. Effects of nitrogen fertilizer, pH, and electrical conductivity on the solubility of cadmium in soil solution. Pedologist, 2010; 53(3): 101-107.

[31] Scott N A, Vernon Cole C, Elliott E T, Huffman S A. Soil textural control on decomposition and soil organic matter dynamics. Soil Science Society of America Journal, 1996; 60(4): 1102-1109.

[32] Moldrup P, Olesena T, Komatsub T, Schjønningc P, Rolstond D E. Tortuosity, diffusivity, and permeability in the soil liquid and gaseous phases. Soil Science Society of America Journal, 2001; 65(3): 613-623.

[33] Bronick C J, Lal R. Soil structure and management: a review. Geoderma, 2005; 124(1-2): 3-22.

[34] Stevenson F J, Cole M A. Cycles of soils: carbon, nitrogen, phosphorus, sulfur, micronutrients. New York: John Wiley \& Sons, 1999.

[35] Parfitt R L, Giltrap D J, Whitton J S. Contribution of organic matter and clay minerals to the cation exchange capacity of soils. Communications in Soil Science and Plant Analysis, 1995; 26(9-10): 1343-1355.

[36] Batjes N H. Total carbon and nitrogen in the soils of the world. European Journal of Soil Science, 1996; 47: 151-163.

[37] D’Odorico P, Bhattachan A, Davis K F, Ravi S, Runyan C W. Global desertification: Drivers and feedbacks. Advances in Water Research, 2013; 51: 326-344.

[38] Knops J M H, Tilman D. Dynamics of soil nitrogen and carbon accumulation for 61 years after agricultural abandonment. Ecology, 2000; 81(1): 88-98.

[39] Post W M, Kwon K C. Soil carbon sequestration and land-use change: Processes and potential. Global Change Biology, 2000; 6(3): 317-327.

[40] Ritchie G S P, Dolling P J. The role of organic matter in soil acidification. Australian Journal of Soil Research, 1985; 23: 569-576.

[41] Turk J K, Graham R C. Soil carbon and nitrogen accumulation in a forested debris flow chronosequence, California. Soil Science Society of America Journal, 2009; 73(5): 1504-1509.

[42] Robertson G P, Klingensmith K M, Klug M J, Paul E A, Crum J R. Soil resources, microbial activity, and primary production across an agricultural ecosystem. Ecological Applications, 1997; 7(1): 158-170.

[43] Fierer N, Schimel J P, Holden P A. Variations in microbial community composition through two soil depth profiles. Soil Biology \& Biochemistry, 2003; 35(1): 167-176.

[44] Cassman K G. Ecological intensification of cereal production systems: yield potential, soil quality, and precision agriculture. Proc. Natl. Acad. Sci. USA, 1999; 96(11): 5952-5959.

[45] Schoenholtz S H, Van Miegroet H, Burger J A. A review of chemical and physical properties as indicators of forest soil quality: challenges and opportunities. Forest Ecology and Management, 2000; 138(1-3): 335-356.

[46] Kitchen N R, Sudduth K A, Drummond S T. Soil electrical conductivity as a crop productivity measure for claypan soils. Journal of Production Agriculture, 1999; 12(4): 607-617.

[47] Corwin D L, Lesch S M. Application of soil electrical conductivity to precision agriculture: theory, principles, and guidelines. Agronomy Journal, 2003; 95(3): 455-471.

[48] Guo J H, Liu X J, Zhang Y, Shen J L, Han W X, Zhang W F, et al. Significant acidification in major Chinese croplands. Science, 2010; 327(5968): 1008-1010.

[49] Vitousek P M, Howarth R W. Nitrogen limitation on land and in the sea: how can it occur? Biogeochemistry, 1991; 13: 87-115.

[50] Kang H, Xin Z, Berg B, Burgess P J, Liu Q, Liu Z, et al. Global pattern of leaf litter nitrogen and phosphorus in woody plants. Annals of Forest Science, 2010; 67: 811

[51] Hassink J. Effects of soil texture and grassland management on soil organic C and $\mathrm{N}$ and rates of $\mathrm{C}$ and $\mathrm{N}$ mineralization. Soil Biology \& Biochemistry, 1994; 26(9): 1221-1231.

[52] Zhou T, Shi P, Hui D, Luo Y. Global pattern of temperature sensitivity of soil heterotrophic respiration $\left(\mathrm{Q}_{10}\right)$ and its implications for carbon-climate feedback. Journal of Geophysical Research, 2009; 114: G02016. doi: 10.1029/2008JG000850.

[53] Raich J M, Schlesinger W H. The global carbon dioxide flux un soil respiration and its relationship to vegetation and climate. Tellus, 1992; 44(2): 81-99. 